\title{
The role of mass media exposure on tuberculosis knowledge and attitude among migrant and seasonal farmworkers in Northwest Ethiopia
}

Kassahun Alemu Gelaye ${ }^{1}$, Getu Debalkie², Tadesse Awoke Ayele', Sintayehu Daba Wami ${ }^{3}$, Malede Mequanent Sisay ${ }^{1}$, Destaw Fetene ${ }^{1}$, Haileab Fekadu Wolde ${ }^{1}$ and Temesgen Yihunie Akalu ${ }^{1 *}$ (D)

\begin{abstract}
Background: Globally, tuberculosis (TB) is the 10th leading cause of death. Despite no country achieved its target, the world health organization (WHO) proposed a 90-90-90 approach to fastening the end TB strategy. Improvement and progression of TB control need good knowledge and a favorable attitude towards the disease. However, interventions designed don't take migrants and seasonal farmworkers into account. Therefore, this study aimed at estimating the level of knowledge and attitude on Tuberculosis among migrant and seasonal farmworkers in northwest Ethiopia.

Methods: Community-based cross-sectional study was conducted in the West Gondar zone from October to November 2018. A two-stage cluster sampling was used to select 949 migrant and seasonal farmworkers. Both bivariate and multivariable logistic regression analyses were performed. A $p$-value of $<0.05$ was used to declare statistical significance. The goodness of fit was checked using Hosmer and Lemeshow test.

Results: In this study, $(41.8 \%),(95 \%$ Cl: $38.73,45.01)$ and $(50.5 \%),(95 \%$ Cl: $47.29,53.65)$ of migrants and seasonal farmworkers had good knowledge and a favorable attitude, respectively. The odds of good knowledge among mass media exposed migrants were $\mathrm{AOR}=1.42,95 \% \mathrm{Cl}$ : $(1.02,2.01)$. Moreover, urban residence and having good knowledge increase the odds of favorable attitude by 1.66 , $(\mathrm{AOR}=1.7 ; 95 \% \mathrm{Cl}: 1.05,2.62)$ and $4.3(\mathrm{AOR}=4.3,95 \% \mathrm{Cl}$ : $3.26,5.75)$, respectively.

Conclusion: In this study, the overall knowledge and attitude of migrant and seasonal farmworkers on TB were low. Family size and mass media exposure significantly affect knowledge of the migrants on TB. On the other hand, the attitude was affected by urban residence, health information, and having good knowledge. Health promotion interventions, focused on TB cause, mode of transmission, prevention, and treatment are important to migrant and seasonal farmworkers to improve the knowledge and attitude of migrants and seasonal farmworkers.
\end{abstract}

Keywords: Knowledge, Attitude, TB, Migrants, And seasonal farmworkers, West Gondar

\footnotetext{
*Correspondence: temesgenyihunie@gmail.com

'Department of Epidemiology and Biostatistics, Institute of Public Health,

University of Gondar, Gondar, Ethiopia

Full list of author information is available at the end of the article
}

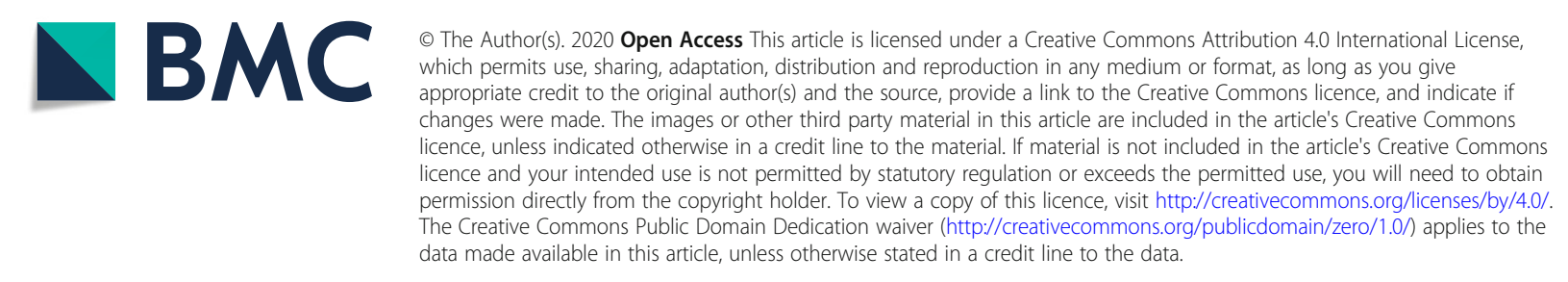




\section{Background}

Tuberculosis (TB) is caused by mycobacterium species which is treatable and curable and it mainly affects the lungs [1]. According to the World Health Organization (WHO) 2019 report, TB resulted in 1.2 million deaths and stands as the 10th leading cause of death, ranking above HIV/AIDS. Ethiopia is among the $30 \mathrm{~TB}$ high burden and 27 high Multi-Drug Resistance (MDR) TB burden countries globally. There was a $27 \%$ reduction from 1.7 million in 2000 and a $60 \%$ reduction from 620,000 in 2000 among HIV negative and HIV positive individuals, respectively [1]. However, according to a global plan to end-TB between 2016 and 2020 no country across the globe achieved a 90-90-90 target [2]. A 90-90-90 global target is defined as by the year $202090 \%$ of all people living with HIV will know their HIV status, $90 \%$ of all the people diagnosed with HIV infection will receive sustained antiretroviral therapy, and $90 \%$ of all people receiving antiretroviral therapy will have viral suppression.

A systematic review and meta-analysis showed that the prevalence of MDR-TB in Ethiopia was 1.4\% [3]. Ethiopia has implemented several TB control efforts including $\mathrm{TB}$ program capacity strengthening at the central and regional level, the involvement of private sectors in TB diagnosis and treatment, expansion of culture, and introduction of Gene-expert for diagnosis, and expansion of MDR treatment centers. As a result, the mortality rate declined from 73 to $32 \%$, treatment success rate improved from 79 to $90 \%$, and the case detection rate increase from 33 to $62 \%$ in the year 2005 to 2014 [4].

Further improvements and progression of TB control need a good understanding of the cause, mode of transmission, prevention and treatment, and favorable attitude. Addressing knowledge gaps in TB prevention has a great role in eliminating TB [5]. Literacy [6, 7], gender [6], mass media [8-10], is a TB patient [11], professional occupation [7, 12], health education [13], culture myths $[14,15]$, knowledge [16], wealth index [17], age [18], and residence [19] were some of the factors affecting knowledge and attitude. Since knowledge is a precursor of a TB control strategy, determining knowledge of migrants and seasonal farmworkers is very crucial in enabling and fastening controlling TB strategies [20].

Despite significant improvement in $\mathrm{TB}$ control and prevention in the country, the evidence on the current knowledge, attitude, and associated factors towards TB in Ethiopia among migrant and seasonal farmworkers are limited. Hence, estimating their knowledge and attitude has a vital role in undertaking measures to fasten the motto of the end TB strategy.

Migrants and seasonal farmworkers are highly vulnerable to Tuberculosis since they are disadvantaged groups. However, to fasten TB control strategy emphasis is only given to smear-positive patients and contact tracing is implemented strongly to minimize the burden of $T B$ [21]. Therefore, addressing the risk of TB in international migrants is an essential component of TB prevention and care efforts in developing countries, and strategies to systematically screen for, diagnose, treat and prevent $\mathrm{TB}$ among this group contribute to national and global TB elimination goals. It is, therefore, this study was aimed at estimating knowledge, attitude, and associated factors on migrant and seasonal farmworkers on TB in the West Gondar zone, northwest Ethiopia.

\section{Methods}

\section{Study setting}

The study was implemented in Amhara Regional State, northwest Ethiopia. Among 167 districts found in the region, migrants and seasonal farmworkers went for work mainly in Metema and West Armachiwo districts. These districts are the two common sites of sesame production in the region where hundreds of thousands of migrants and seasonal farmworkers traveled during planting, weeding, and harvesting seasons (Fig. 1).

\section{Population, sample size determination, and procedure}

All seasonal and migrant farmworkers in the West Gondar zone from October 2018 to November 2018 were included in the study. A pilot study was conducted among 50 migrants and seasonal farmworkers in Quara district, West Gondar zone to determine the minimum sample size. Then sample size was determined using a single population formula by using the following assumptions. Based on the evidence from the pilot study the proportion of good knowledge and favorable attitude were 44 and 53\%, respectively. Besides, 95\% CI, 5\% margin of error and a $10 \%$ non-response rate were used. Since the sampling technique was cluster; the design effect of 2 was also used. Therefore, a total of 796 and 804 study participants were required for knowledge and attitude, respectively. To estimate predictors, the sample size was computed using assumptions of power, 80, 95\%CI, odds ratio $1.5-1.8$ for the predictors of health information, occupation, and knowledge. Finally, the largest sample size of 976 was used.

A two-stage cluster sampling technique was used. In the first stage, the farm companies were randomly selected, and then seasonal migrant workers were randomly selected.

\section{Data collection tool and procedure}

A pretested and structured questionnaire was used to collect data on knowledge, attitude, and health-seeking behavior on TB. The tool was prepared first in English then translated into the local language (Amharic). Then it was re-translated to English by language experts to keep 


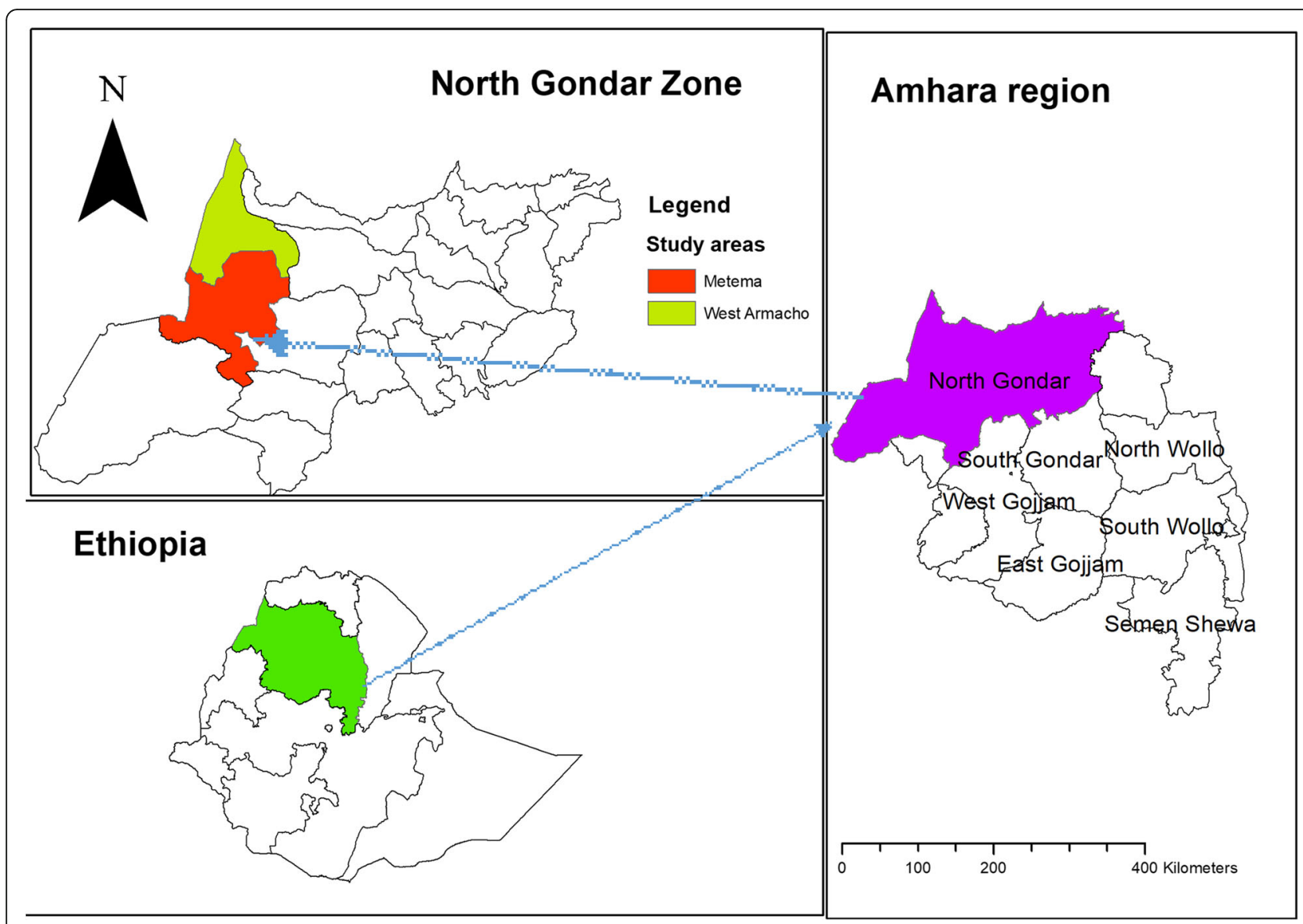

Fig. 1 Map of the study area (constructed by authors using ArcGIS version 10.6)

its consistency. The questionnaire consisted of 43 questions, divided into two parts. The first part addressed socio-demographic characteristics and sources of information. The second component includes TB knowledge, attitude, and health-seeking behavior. The data was collected by interviewing through 10 trained BSc nurses. Four supervisors control the overall data collection process. We had two groups of data collectors. The first group which consisted of 5 data collectors enrolled in the Metema district and other equal numbers of data collectors collect the data in the West Armacho district. Before going to actual data collection, two-day training was given to all data collectors and supervisors. Supervisors closely monitored the interviewing process on a daily base.

In this study, the outcome variables were knowledge about TB and attitude about TB. Briefly, knowledge was assessed by 23 questions that addressed the etiology, symptoms, transmission, prevention, and treatment. Respondents who answered $12(>=50 \%)$ of these questions were defined as having good knowledge and vice versa. Furthermore, the attitude was assessed by five-item Likert scale questions and respondents who had a positive attitude towards three of the questions $(60 \%)$ were classified as having a favorable attitude. The independent variables include: region, sex, age, family size, education status, occupation, residence, religion, marital status, income, number of visits, and length of stay were included. The income status of respondents was dichotomized into low and high income. Low income was defined as respondents who gain less than the median (120 birr's). Moreover, the source of information data was also collected from respondents.

\section{Statistical analysis}

Epi Data version 3.1 was used for data entry and the analysis was performed using Stata version 14. Coding, recoding, computing, and data cleaning were computed. Frequencies and proportions were used to describe the data. A chi-square test was checked to assess the relationship between two categorical variables. The bivariate analysis was performed and variables that were significant at $p$-value $<0.2$ were entered in the multivariable analysis. To examine the association between independent variables and the outcome variables multivariable logistic regression analysis was performed. In the multivariable logistic regression analysis, $p$-value $<0.05$ was used to declare statistical significance association. 
Table 1 Socio-demographic and economic characteristics of migrant and seasonal farmworkers in West Gondar zone, northwest Ethiopia $2018(N=949)$

\begin{tabular}{l}
\hline Variables \\
\hline Region \\
Tigray \\
Amhara \\
Oromia \\
Sex \\
Male \\
Female \\
Age \\
$13-20$ \\
$21-29$ \\
$30-39$ \\
$40-67$ \\
Family size in their family \\
$1-2$ \\
$3-5$ \\
$6-14$
\end{tabular}

\section{Educational status}

Unable to read and write

Able to read and write

Primary education

Secondary education

Occupation before departure

Student

Farmer

Unemployed

\section{Residence}

Rural

Urban

\section{Religion}

Orthodox

Muslim

Protestant

Catholic

\section{Marital status}

Single

Married

Divorce

Income

Low

High

Number of visits to the farms
Frequency (\%)

$27(2.8)$

917(96.6)

$5(0.5)$

$942(99.3)$

$7(0.7)$

$244(25.7)$

$484(51.0)$

151 (15.9)

$70(7.4)$

$88(9.3)$

$536(56.5)$

$325(34.2)$

$374(39.4)$

$73(7.7)$

405 (42.7)

$97(10.2)$

177 (18.7)

$644(67.8)$

$128(13.5)$

831 (87.6)

118 (12.4)

931 (98.1)

15 (1.6)

$1(0.1)$

$2(0.2)$

648 (68.3)

243 (25.6)

$58(6.1)$

496 (52.3)

$453(47.7)$

$178(18.8)$
Table 1 Socio-demographic and economic characteristics of migrant and seasonal farmworkers in West Gondar zone, northwest Ethiopia 2018 ( $N=949)$ (Continued)

\begin{tabular}{ll}
\hline Variables & Frequency (\%) \\
\hline $2-4$ & $293(30.9)$ \\
$5-8$ & $280(29.5)$ \\
$\geq 9$ & $198(20.8)$ \\
Length of stay & \\
Less than two month & $576(60.7)$ \\
Two months and above & $373(39.3)$ \\
\hline
\end{tabular}

Multi-collinearity was assessed using the variance inflation factor (VIF) and considered no multi-collinearity lower than 10 . Odds ratio with $95 \% \mathrm{CI}$ was used to measuring the strength of the association. The goodness of fit was 0.54 and 0.76 for knowledge and attitude, respectively.

\section{Results}

Socio-demographic and economic factors

The response rate of the study was $97.23 \%$. The mean age of respondents was $26.05 \pm 7.82$ years. Of all respondents, 917 (96.6\%) were from the Amhara region. The majority, $728(76.21 \%)$ were in the age group of $13-29$ years. The median family size of respondents was 5 with the Inter Quartile Range (IQR = 4-6). Of all, $447(47.1 \%)$ had no formal education. About 644 (68\%) and177 (19\%) of migrants and seasonal workers were farmers and students by occupation, respectively. The median daily income of respondents was 120 Birr with IQR of 100-150 Birr. Regarding residence, 831 (87.57\%) were rural dwellers. Only 178 (18.76\%) of migrant and seasonal farmworkers had one visit (Table 1).

\section{Source of information of respondents}

Five hundred sixty-five (59.54\%) heard information about $\mathrm{TB}$ at different sources. Of these, 328 (58.05\%) heard from mass media, and the majority, 508 (90.07\%) obtained health information from health workers. Also, 270 (47.96\%) obtained from friends/families, 90 (15.96\%) reading posters and 145 (25.75\%) from school.

\section{Knowledge on tuberculosis}

In this study, 758 (79.87\%) of respondents be acquainted with the cause of TB as germ/bacteria. Regarding symptoms of $\mathrm{TB}, 721(75.97 \%)$ respondents and nearly half $(45.63 \%)$ know TB patients had persistent cough and sputum with blood, respectively. Nearly one-third of 351 (36.99\%) of respondents know that TB patients had a fever. Of all, $732(77.13 \%)$ of respondents know that TB is transmittable. Five hundred thirty-three, 533 (56.16\%) know that TB transmission can be prevented by minimizing close 
Table 2 Knowledge on Cause, symptoms, methods of transmission and prevention of tuberculosis among migrant and seasonal farmworkers in West Gondar zone, $2018(n=949)$

Variables $\quad$ Frequency (\%)

Cause of Tuberculosis germ/bacteria

Yes

758(79.9)

No

$191(20.1)$

Persistent cough

Yes

$721(75.97)$

No

228(24.03)

Sputum with blood

Yes

$433(45.63)$

No

Fever

Yes

No

Poor apatite

Yes

No

Night sweating

Yes

No

Weight loss

Yes

No

Chest pain

Yes

No

Transmit through cough/sneezing

Yes

No

Via touching TB person

Yes

No

Through sharing utensils

Yes

No

By sexual contact

Yes

No

By drink unboiled milk

Yes

No

TB is preventable

$168(17.7)$

$781(82.3)$

$240(25.3)$

$709(74.7)$

$686(72.4)$

262 (27.6)
Table 2 Knowledge on Cause, symptoms, methods of transmission and prevention of tuberculosis among migrant and seasonal farmworkers in West Gondar zone, $2018(n=949)$ (Continued)

\begin{tabular}{|c|c|}
\hline Variables & Frequency (\%) \\
\hline \multicolumn{2}{|c|}{ Minimizing close contact } \\
\hline Yes & $533(56.2)$ \\
\hline No & $416(43.8)$ \\
\hline \multicolumn{2}{|c|}{ Covering mouth while coughing } \\
\hline Yes & $468(49.3)$ \\
\hline No & $481(50.7)$ \\
\hline \multicolumn{2}{|c|}{ Avoid sharing utensils } \\
\hline Yes & $445(46.9)$ \\
\hline No & $504(53.1)$ \\
\hline \multicolumn{2}{|l|}{ Early treatment } \\
\hline Yes & $410(43.2)$ \\
\hline No & $539(56.8)$ \\
\hline \multicolumn{2}{|l|}{ Good nutrition } \\
\hline Yes & $315(33.2)$ \\
\hline No & $634(66.8)$ \\
\hline \multicolumn{2}{|c|}{ Using separate rooms } \\
\hline Yes & $371(39.1)$ \\
\hline No & $578(60.9)$ \\
\hline \multicolumn{2}{|c|}{ Close opening windows } \\
\hline Yes & $232(24.4)$ \\
\hline No & $717(75.6)$ \\
\hline \multicolumn{2}{|l|}{ Using modern drugs } \\
\hline Yes & $762(78.3)$ \\
\hline No & $211(21.7)$ \\
\hline \multicolumn{2}{|l|}{ Nutritional support } \\
\hline Yes & $38(3.9)$ \\
\hline No & $935(96.1)$ \\
\hline \multicolumn{2}{|l|}{ TB is not treatable } \\
\hline Yes & $192(20.2)$ \\
\hline No & $757(79.8)$ \\
\hline \multicolumn{2}{|c|}{ Overall TB knowledge } \\
\hline Poor knowledge & $552(58.2)$ \\
\hline Good knowledge & $397(41.8)$ \\
\hline
\end{tabular}

contact. Regarding on treatment of TB, 785 (82.72\%) know that TB can be prevented. In this study, $41.83 \%$ (95\%CI: $38.73,45.01)$ of migrant and seasonal farmworkers were knowledgeable (Table 2).

The attitude of respondents on tuberculosis

The majority, 655 (67.93\%) believed TB is a very serious disease and only $294(30.2 \%)$ believed TB is a serious problem in their community. Six hundred eighty-three 
(72.0\%) mentioned that they would not feel feared or ashamed if they would have TB. Of all, 275 (28.35\%) believed that some people are more likely to be affected by TB than others. Three hundred sixty-six (38.57\%) would not show any feeling of compassion and desire to help TB patients. The overall favorable attitude was observed in nearly $50 \%$ of respondents $50.47 \%$ (95\% CI: 47.29 53.65) (Table 3).

\section{Health seeking behavior}

Four hundred ninety-two (51.82\%) respondents would go to doctor/health professional if they had TB. Besides, 175 (18.44\%) and 175 (18.44\%) respondents respond they would contact parents and close friends, respectively if they had TB. Of all, 708 (74.60\%) would seek medical care if the symptoms last for greater than 2 weeks. Two hundred (21.07\%) would seek medical care as soon as they realized the symptoms. The remaining, $41(4.32 \%)$ would seek medical care when my treatment doesn't work. From 552 respondents with poor knowledge, 62 (11.23\%) had good seeking behavior. On the other hand among 397 respondents with good knowledge 93 (23.43\%) had good health-seeking behavior.

\section{Associated factors with knowledge of respondents}

In the bivariate analysis seven factors including educational status, family size, daily income, mass media exposure, obtain health information from friends, health information from posters, and hearing health information from school became significant at $p$-value less than 0.2 . However, in multivariable analysis, only family size and mass media exposure retained significantly. The odds of having good knowledge among respondents having $3-5$ and $>=6$ families were increased by 80 and $85 \%$, respectively compared to respondents having less than three families. The odds of good knowledge were increased by $42 \%$ among respondents having mass media exposure compared to their counterparts (Table 4).

\section{Associated factors with attitude of respondents}

In the bivariate analysis educational status, occupation, family size, residency, health information, and knowledge were statistically significant. However, in the multivariate logistic regression analysis, only three variables (Health information, residence, and knowledge) were statistically significant factors to have a favorable attitude. The odds of having a favorable attitude among urban dwellers were increased by $63 \%$ compared with rural counterparts. The odds of favorable attitude on TB among respondents who had health information were increased by $72 \%$ compared with their counterparts. The odds of favorable attitudes were 4.3 times higher among
Table 3 Attitude of respondents on Tuberculosis among migrant and seasonal workers in West Gondar, 2018 ( $N=949)$

\begin{tabular}{ll}
\hline Variables & Frequency (\%) \\
\hline How serious are the diseases TB? & $655(67.9)$ \\
Very serious & $188(20.9)$ \\
Somewhat serious & $90(9.5)$ \\
Not serious & $16(1.7)$ \\
Not very serious & $294(30.2)$ \\
How serious is the problem TB in your working area? \\
Very serious & $223(22.9)$ \\
Somewhat serious & $249(25.6)$ \\
Not serious & $207(21.3)$ \\
Not very serious
\end{tabular}

What would be your reaction if you were found to have TB?

$\begin{array}{ll}\text { Fear } & 379(39.9) \\ \text { Surprised } & 80(8.4) \\ \text { Shame } & 14(1.5) \\ \text { Sadness or hopeless } & 123(13.0) \\ \text { No special feeling } & 353(37.2)\end{array}$

Do you think some people are more likely to become infected than others?

Yes

$268(28.2)$

No

$681(71.8)$

How is your feeling towards people with TB?

$\begin{array}{ll}\text { Compassion and desire to help } & 583(61.4) \\ \text { Compassion but stay away from them } & 109(11.5) \\ \text { It is their problem and I cannot get TB } & 9(1.0) \\ \text { I fear them because they may infect me } & 94(9.9) \\ \text { I have no particular feeling } & 154(16.2)\end{array}$

In your community (working area) how is a person who has TB usually regarded/treated?

$\begin{array}{ll}\text { Most people reject him or her } & 81(8.5) \\ \begin{array}{l}\text { Most people are friendly, but they try to avoid } \\ \text { him/ her }\end{array} & 398(42.1) \\ \text { Mostly supports and helps him/ her } & 299(31.5) \\ \text { not sure whether they help/ not } & 97(10.2) \\ \text { Don't give special attention } & 74(7.7) \\ \text { The overall favorable attitude } & \\ \text { Poor attitude } & 470(49.5) \\ \text { Favorable attitude } & 479(50.5)\end{array}$

participants with good knowledge compared with their counterparts (Table 5).

\section{Discussion}

This study revealed that there are a low knowledge and attitude on TB among migrant and seasonal farmworkers. Only $41.83 \%$ of migrants and seasonal farmworkers were knowledgeable. Furthermore, $50.47 \%$ had a favorable 
Table 4 Bi-variable and multivariable logistic regression analysis among migrants and seasonal farmworkers on the of knowledge about tuberculosis in West Armacho, Ethiopia $(N=949)$

\begin{tabular}{|c|c|c|c|c|}
\hline \multirow[t]{2}{*}{ Characteristics } & \multicolumn{2}{|c|}{ Knowledge status } & \multirow{2}{*}{$\begin{array}{l}\text { COR with 95\% } \\
\mathrm{Cl}\end{array}$} & \multirow[t]{2}{*}{ AOR with $95 \%$} \\
\hline & Good & Poor & & \\
\hline \multicolumn{5}{|l|}{ Education status } \\
\hline Unable to read and write & 147 & 227 & 1 & 1 \\
\hline Able to read and write & 29 & 44 & $1.02(0.61-1.70)$ & $0.94(0.56,1.59)$ \\
\hline Primary & 180 & 225 & $1.24(0.93,1.64)$ & $1.09(0.81,1.49)$ \\
\hline Secondary and above & 41 & 56 & $1.13(0.72,1.78)$ & $0.87(0.52,1.45)$ \\
\hline \multicolumn{5}{|l|}{ Family size } \\
\hline $1-2$ & 28 & 60 & 1 & 1 \\
\hline $3-5$ & 227 & 309 & $1.57(0.97,2.54)$ & $1.80(1.09,2.96)^{*}$ \\
\hline$>=6$ & 142 & 183 & $1.66(1.01,2.74)$ & $1.85(1.11,3.10)^{*}$ \\
\hline \multicolumn{5}{|l|}{ Daily income } \\
\hline Low & 222 & 274 & $1.29(0.99,1.67)$ & $1.28(0.98,1.67)$ \\
\hline High & 175 & 278 & 1 & 1 \\
\hline \multicolumn{5}{|l|}{ Mass media exposure } \\
\hline No & 228 & 393 & 1 & 1 \\
\hline Yes & 169 & 159 & $1.83(1.39,2.40)$ & $1.42(1.02,2.01)^{*}$ \\
\hline \multicolumn{5}{|c|}{ Friends as sources of information } \\
\hline No & 252 & 427 & 1 & 1 \\
\hline Yes & 145 & 125 & $1.97(1.48,2.61)$ & $1.41(0.97,2.05)$ \\
\hline \multicolumn{5}{|c|}{ Poster as sources of information } \\
\hline No & 342 & 517 & 1 & 1 \\
\hline Yes & 55 & 35 & $2.38(1.51,3.71)$ & $1.65(0.97,2.83)$ \\
\hline \multicolumn{5}{|c|}{ Scholars sources of information } \\
\hline No & 321 & 483 & 1 & 1 \\
\hline Yes & 76 & 69 & $1.66(1.16,2.36)$ & $1.07(0.68,1.70)$ \\
\hline
\end{tabular}

attitude towards TB. TB knowledge among migrants and seasonal farmworkers were significantly affected by mass media exposure and family size. On the other hand, their level of attitude was affected by health information, residence, and knowledge of respondents. Besides, 708 (74.60\%) would seek medical care if the symptoms last for greater than 2 weeks.

In our study, $41.85 \%$ of migrant and seasonal farmworkers were knowledgeable. This finding was in line with the finding from EDHS 2011 (44.14\%) [17]. However, the finding was lower than a study conducted in Lesotho (59.9\%) (22)and Zimbabwe (73.8\%) [22]. This could be due to almost all (98.3\%) of respondents in Lesotho and 93\% in Zimbabwe had formal education. However, only $52.90 \%$ of respondents had formal education in the current study. This could be because a high level of education is usually catalyzed awareness of $\mathrm{TB}$, which acts as a precursor to having good knowledge [23]. Also, a study from Indonesia showed that education is an antecedent of knowledge and has a great contribution to fortifying respondent's knowledge [24]. A case-control study conducted in Sudan showed that $66.5 \%$ of respondents had good knowledge which is higher than the present study [19]. This could be due to nearly half of the respondents were cases, which have information about their disease status and get advice during their follow up. Furthermore, a study from Iran showed that $62.04 \%$ had good knowledge [25]. This difference could be due to defining the outcome variable. In the current study, good knowledge was defined if a respondent correctly answered more than half of the questions. Whereas, in Iran, study mean score was used to classify as knowledgeable.

There is a significant increase in knowledge among mass media exposed migrants and seasonal farmworkers. This finding is in agreement with a study conducted in a general population of Lesotho [26] and India [27]. This is because mass media campaign has a big role in enhancing the normal passive case 
Table 5 Factors related to the level of attitude about tuberculosis among West Gondar, Ethiopia Migrants and seasonal workers in the bivariate and multivariate logistic regression analysis $(N=949)$

\begin{tabular}{|c|c|c|c|c|}
\hline \multirow[t]{2}{*}{ Variables } & \multicolumn{2}{|c|}{ Attitude status } & \multirow{2}{*}{$\begin{array}{l}\text { COR with 95\% } \\
\mathrm{Cl}\end{array}$} & \multirow{2}{*}{$\begin{array}{l}\text { AOR with 95\% } \\
\mathrm{Cl}\end{array}$} \\
\hline & Favorable & unfavorable & & \\
\hline \multicolumn{5}{|l|}{ Educational status } \\
\hline Unable to read and write & 180 & 194 & 1 & 1 \\
\hline Able to read and write & 30 & 43 & $0.75(0.45,1.25)$ & $0.68(0.39,1.17)$ \\
\hline Primary & 208 & 197 & $1.14(0.86,1.5)$ & $0.68(0.64,1.25)$ \\
\hline Secondary and above & 61 & 36 & $1.83(1.15,2.89)$ & $1.31(0.75,2.29)$ \\
\hline \multicolumn{5}{|l|}{ Residence } \\
\hline Rural & 407 & 424 & 1 & 1 \\
\hline Urban & 72 & 46 & $1.63(1.09,2.42)$ & $1.66(1.05,2.62)^{*}$ \\
\hline \multicolumn{5}{|l|}{ Occupation } \\
\hline Student & 108 & 69 & 1 & 1 \\
\hline Farmer & 309 & 335 & $0.59(0.42,0.83)$ & $0.72(0.47,1.10)$ \\
\hline Unemployed & 62 & 66 & $0.60(0.38,0.95)$ & $0.68(0.40,1.15)$ \\
\hline \multicolumn{5}{|l|}{ Family size } \\
\hline $1-2$ & 37 & 51 & 1 & 1 \\
\hline $3-5$ & 278 & 258 & $1.49(0.94,2.34)$ & $1.50(0.90,2.49)$ \\
\hline 6 and above & 161 & 164 & $1.40(0.87,2.26)$ & $1.37(0.81,2.34)$ \\
\hline \multicolumn{5}{|l|}{ Health information } \\
\hline No & 163 & 221 & 1 & 1 \\
\hline Yes & 316 & 249 & $1.72(1.32,2.24)$ & $1.64(1.23,2.18)^{*}$ \\
\hline \multicolumn{5}{|l|}{ Knowledge status } \\
\hline Poor knowledge & 198 & 354 & 1 & 1 \\
\hline Good knowledge & 281 & 116 & $4.33(3.28,5.72)$ & $4.33(3.26,5.75)$ \\
\hline
\end{tabular}

${ }^{*} p$-value $<0.05$

finding strategy by reaching a large population at a time and it provides information regarding on earliest symptoms, cause, and transmission, prevention, and treatment modalities. Accordingly, a study from Colombia showed that mass media exposure was associated with a high level of knowledge and recommended that it should be sustainable to have a long term change to adopt behavioral change and create a habit to use [28]. Moreover, health information through mass media and other methods was significantly affecting the attitude of respondents. This could be the fact that mass media has a great role in creating awareness [29], which can later change perceptions and behaviors' of respondents [30, 31].

Family size is another significant factor affecting the knowledge status of migrants and seasonal farmworkers. This finding is supported by a study conducted in Thailand among the general population and risk groups [18]. This could be due to the culture of sharing information among the family members to one another if family size is large. Also, in a large family, there could be at least one educated person who could transmit a message regarding $\mathrm{TB}$ during any discussion in the household.

Nearly half of migrants and seasonal farmworkers had a favorable attitude. This finding is lower than a study conducted in Timor Leste $(83.3 \%$ in men and $88.6 \%$ in women) [32]. This could be due to the difference in defining the outcome variable. In the former study, a favorable attitude was measured for specific questions (intention to initiate $\mathrm{TB}$ treatment). However, in the current study favorable attitude was measured by creating a composite score and the one who scored more than half the attitude question. Similarly, our study was much lower than a community study from Botswana which showed about $92 \%$ of respondents to have a favorable attitude [33].

Good knowledge was associated with a favorable attitude. This finding is supported by a study conducted in Nigeria [7]. This could be because of good knowledge influence attitude formation [30]. Furthermore, it was supported by a study from Ethiopia among pastoralist communities which showed lower awareness as risk factors for unfavorable attitudes [34]. 
This could be mainly due to perceiving a higher stigma on TB patients among pastoralists with poor awareness.

The strength of the study was determining knowledge, attitude, and factors on TB among migrant and seasonal farmworkers in Ethiopia. This is the first study to evaluate migrant's knowledge and attitude in the context of one of the developing countries, Ethiopia. This study has some limitations. Initially, the study could not allow establishing cause-effect relationships because of cross-sectional nature. Besides, this study could be vulnerable to social desirability bias. There was also a scarcity of literature among migrants and seasonal farmworkers in developing countries. The conducted studies have relied on the general population not specifically on migrants. Finally, this study also suffers from recall bias due to data was collected about their previous experience.

The findings of this study would contribute significantly to design tailored interventions intended in increasing awareness through the use of mass media and developing a favorable attitude in migrants and seasonal farmworkers towards TB. Furthermore, this finding provokes policymakers to design programs and to implement appropriate public health strategies targeted migrants and seasonal farmworkers. As a result, improving the level of knowledge and attitude has paramount importance in the control and elimination of TB cases. Therefore, it is compulsory to do on migrants and seasonal farmworkers to control and eliminate TB in the country.

\section{Conclusion}

This study revealed low overall knowledge and attitudes of migrant and seasonal farmworkers. Mass media exposure and family size significantly affect the knowledge of respondents. Moreover, health information, urban residency, and good knowledge were the main identified factors of a favorable attitude. Health education interventions, focused on TB cause, mode of transmission, prevention, and treatment are important to migrants and seasonal farmworkers. Besides, the role of mass media should be strengthened to improve the knowledge and attitude of migrants and seasonal farmworkers.

\section{Supplementary information}

Supplementary information accompanies this paper at https://doi.org/10. 1186/s12879-020-05316-9.

Additional file 1. The questionnaire developed for this study is provided as Additional File 1.

\section{Abbreviations}

AOR: Adjusted Odds Ratio; BSc: Bachelor of Science; Cl: Confidence Interval; COR: Crude Odds Ratio; EDHS: Ethiopia Demographic Health Survey;
HIV: Human Immunodeficiency Virus; IQR: Inter Quartile Range; MDR: MultiDrug Resistance; TB: Tuberculosis; WHO: World Health Organization

\section{Acknowledgments}

Firstly, we would like to forward our kindest regards to our study participants. We extend our thanks to data collectors and supervisors without them the report will not be materialized. At last but not least, the authors would forward great thanks to the University of Gondar for financial support.

\section{Consent to publication}

Not applicable.

\section{Authors' contributions}

KA selects the title, develops the proposal, interpreted the data, and prepared the manuscript. GD participated in the title selection, proposal development, and manuscript preparation. TA participated in proposal development and manuscript preparation. SD participated in proposal development and manuscript preparation. MM, DF and HF assisted the design, commented on the proposal, and approved it. Besides, they also participated in the preparation of the manuscript. TY selects the title, develops the proposal, collected, analyzed, and interpreted the data and prepared the manuscript. All authors read and approved the final manuscript.

\section{Funding}

This work was supported financially by the University of Gondar. However, the University had no role in study design, data collections, and analysis, decision to publish, or preparation of the manuscript.

Availability of data and materials

Data will be available from the corresponding author upon request.

\section{Ethics approval and consent to participate}

The study protocol was approved by the ethical review committee of the College of Medicine and Health Sciences, University of Gondar. Besides, we took ethical approval from Amhara Public Health Institute. Verbal informed consent was taken from all respondents enrolled in the study and this was approved by the Institutional review board (IRB). Written informed consent was not taken since several participants were unable to read and write and the study involves no more than minimal risk. Also, for children between 13 and 18 years, permission was obtained from the farm leaders and assent was obtained from children themselves based on a child's level of comprehension. In this case for children between 13 and 18 years the IRB gave a waiver. To keep confidentiality, respondent's names and other personal identifiers were not included. The collected data were password protected.

\section{Competing interests}

There is no competing of interests related to this work.

\section{Author details}

${ }^{1}$ Department of Epidemiology and Biostatistics, Institute of Public Health, University of Gondar, Gondar, Ethiopia. ${ }^{2}$ Department of Health Education and Behavioral Science, Institute of Public Health, University of Gondar, Gondar, Ethiopia. ${ }^{3}$ Department of Environmental and Occupational Health and Safety, Institute of Public Health, University of Gondar, Gondar, Ethiopia.

Received: 16 January 2020 Accepted: 30 July 2020

Published online: 05 August 2020

References

1. Assefa $\mathrm{E}$, Tadesse M. Factors related to the use of antenatal care services in Ethiopia: application of the zero-inflated negative binomial model. Women Health. 2017;57(7):804-21.

2. Cousins S. Progress towards TB reduction targets is faltering, report finds. BMJ. 2017;359:j4758.

3. Asgedom SW, Teweldemedhin M, Gebreyesus H. Prevalence of multidrugresistant tuberculosis and associated factors in Ethiopia: a systematic review. J Pathog. 2018;2018:7104921. 
4. The 12th national tb research annual conference and commemoration of world tb day.

5. DeLuca A, Dhumal G, Paradkar M, Suryavanshi N, Mave V, Kohli R, et al. Addressing knowledge gaps and prevention for tuberculosis-infected Indian adults: a vital part of elimination. BMC Infect Dis. 2018;18(1):202.

6. Abbasi A, Rafique M, Saghir A, Abbas K, Shaheen S, Abdullah F. Gender and occupation wise knowledge, awareness and prevention of tuberculosis among people of district Muzaffarabad AJ \& K. Pak J Pharm Sci. 2016;29(6):1959-68.

7. Balogun MR, Sekoni AO, Meloni ST, Odukoya OO, Onajole AT, Longe-Peters $\mathrm{OA}$, et al. Predictors of tuberculosis knowledge, attitudes and practices in urban slums in Nigeria: a cross-sectional study. Pan Afr Med J. 2019;32:60.

8. Arroyo Rojas L, Sanchez Valdes CL, Bonne Carcasses MA, Perez Perez HR, Armas PL. Knowledge and perception about tuberculosis in Habana Vieja municipality. Rev Cubana Med Trop. 2012;64(3):268-78.

9. Gebrehiwot TT, Tesfamichael FA. Knowledge, risk perception and practice regarding tuberculosis transmission among long distance bus drivers in Addis Ababa, Ethiopia: a cross sectional study. Ethiop J Health Sci. 2017; 27(6):601-12.

10. Geraee N, Kaveh MH, Shojaeizadeh D, Tabatabaee HR. Impact of media literacy education on knowledge and behavioral intention of adolescents in dealing with media messages according to stages of change. J Adv Med Educ Professionalism. 2015;3(1):9-14.

11. Badane AA, Dedefo MG, Genamo ES, Bekele NA. Knowledge and healthcare seeking behavior of tuberculosis patients attending Gimbi general hospital, West Ethiopia. Ethiop J Health Sci. 2018;28(5):529-38.

12. Hossain S, Zaman K, Quaiyum A, Banu S, Husain A, Islam A, et al. Factors associated with poor knowledge among adults on tuberculosis in Bangladesh: results from a nationwide survey. J Health Popul Nutr. 2015;34:2.

13. Bisallah Cl, Rampal L, Lye MS, Mohd Sidik S, Ibrahim N, lliyasu Z, et al. Effectiveness of health education intervention in improving knowledge, attitude, and practices regarding tuberculosis among HIV patients in general hospital Minna, Nigeria - a randomized control trial. PLoS One. 2018; 13(2):e0192276.

14. Craig GM, Daftary A, Engel N, O'Driscoll S, loannaki A. Tuberculosis stigma as a social determinant of health: a systematic mapping review of research in low incidence countries. Int J Infect Dis. 2017;56:90-100.

15. Gil N, Lopez L, Rodriguez D, Rondon M, Betancourt A, Gutierrez B, et al. Myths and realities about knowledge, attitudes and practices of household contacts of tuberculosis patients. Int J Tuberc Lung Dis. 2018;22(11):1293-9.

16. Fabrigar LR, Petty RE, Smith SM, Crites SL Jr. Understanding knowledge effects on attitude-behavior consistency: the role of relevance, complexity, and amount of knowledge. J Pers Soc Psychol. 2006;90(4):556-77.

17. Gelaw SM. Socioeconomic factors associated with knowledge on tuberculosis among adults in Ethiopia. Tuberc Res Treat. 2016;2016:6207457.

18. Pengpid S, Peltzer K, Puckpinyo A, Tiraphat S, Viripiromgool S, Apidechkul T, et al. Knowledge, attitudes, and practices about tuberculosis and choice of communication channels in Thailand. J Infect Dev Ctries. 2016;10(7):694-703.

19. Suleiman MM, Sahal N, Sodemann M, Elsony A, Aro AR. Tuberculosis awareness in Gezira, Sudan: knowledge, attitude and practice case-control survey. East Mediterr Health J. 2014;20(2):120-9.

20. Hassan AO, Olukolade R, Ogbuji QC, Afolabi S, Okwuonye LC, Kusimo OC, et al. Knowledge about tuberculosis: a precursor to effective TB controlfindings from a follow-up national KAP study on tuberculosis among Nigerians. Tuberc Res Treat. 2017;2017:6309092.

21. Umar AS. Does female education explain the disparity in the use of antenatal and natal services in Nigeria? Evidence from demographic and health survey data. Afr Health Sci. 2017;17(2):391-9.

22. Musuka G, Teveredzi V, Mutenherwa F, Chingombe I, Mapingure M. Tuberculosis knowledge, misconceptions/myths in adults: findings from Lesotho, Malawi, Namibia and Zambia demographic health surveys (20132016). BMC Res Notes. 2018;11(1):778.

23. Miandad M, Nawaz-UI-Huda S, Burke F, Hamza S, Azam M. Educational status and awareness among tuberculosis patients of Karachi. J Pak Med Assoc. 2016;66(3):265-9.

24. Mondal MN, Nazrul HM, Chowdhury MR, Howard J. Socio-demographic factors affecting knowledge level of tuberculosis patients in Rajshahi City, Bangladesh. Afr Health Sci. 2014;14(4):855-65.

25. Bagheri Amiri F, Doosti-Irani A, Sedaghat A, Fahimfar N, Mostafavi E. Knowledge, attitude, and practices regarding HIV and TB among homeless people in Tehran, Iran. Int J Health Policy Manag. 2017;7(6):549-55.
26. Luba TR, Tang S, Liu Q, Gebremedhin SA, Kisasi MD, Feng Z. Knowledge, attitude and associated factors towards tuberculosis in Lesotho: a population based study. BMC Infect Dis. 2019;19(1):96.

27. Sharma AK, Sharma R. Impact of mass media on knowledge about tuberculosis control among homemakers in Delhi. Int J Tuberc Lung Dis. 2007;11(8):893-7.

28. Jaramillo E. The impact of media-based health education on tuberculosis diagnosis in Cali, Colombia. Health Policy Plan. 2001;16(1):68-73.

29. Nglazi MD, Bekker LG, Wood R, Shey MS, Uthman OA, Wiysonge CS. The impact of mass media interventions on tuberculosis awareness, healthseeking behaviour and health service utilisation: a systematic review protocol. BMJ Open. 2014;4(1):e004302.

30. Zhu X, Xie X. Effects of knowledge on attitude formation and change toward genetically modified foods. Risk Anal. 2015;35(5):790-810.

31. Hatzenbuehler LA, Starke JR, Smith EO, Turner TL, Balmer DF, Arif Z, et al. Increased adolescent knowledge and behavior following a one-time educational intervention about tuberculosis. Patient Educ Couns. 2017; 100(5):950-6.

32. Pengpid S, Peltzer K. Knowledge, attitudes, and practices regarding tuberculosis in Timor-Leste: results from the demographic and health survey 2016. J Prev Med Public Health. 2019;52(2):115-22.

33. Musuka G, Teveredzi V, Busang L, Chingombe I, Makadzange P, Mokgweetsinyana S, et al. Community attitudes on tuberculosis in Botswana: an opportunity for improving the National Tuberculosis Programme outcomes, 2011. BMC Res Notes. 2018;11(1):499.

34. Sima BT, Belachew T, Abebe F. Knowledge, attitude and perceived stigma towards tuberculosis among pastoralists; do they differ from sedentary communities? A comparative cross-sectional study. PLoS One. 2017;12(7): e0181032.

\section{Publisher's Note}

Springer Nature remains neutral with regard to jurisdictional claims in published maps and institutional affiliations.
Ready to submit your research? Choose BMC and benefit from:
- fast, convenient online submission
- thorough peer review by experienced researchers in your field
- rapid publication on acceptance
- support for research data, including large and complex data types
- gold Open Access which fosters wider collaboration and increased citations
- maximum visibility for your research: over $100 \mathrm{M}$ website views per year
At BMC, research is always in progress.
Learn more biomedcentral.com/submissions 